\title{
Effect of the initial water activity on the yields and molecular wWeights of the lipase-catalysed synthesis of aliphatic polyesters in low pressure liquid R-134a
}

\author{
Roeb García-Arrazola, Miquel Gimeno, * Eduardo Bárzana* \\ *Universidad Nacional Autónoma de México, Facultad de Química, Dpto. Alimentos y \\ Biotecnología. Ciudad Universitaria, México D.F., 04510, México; E-mails: ebg@ \\ servidor.unam.mx, mgimeno@servidor.unam.mx.
}

(Received: 28 September, 2007; published: 30 January, 2008)

\begin{abstract}
The enzymatic synthesis of the polyester poly(epsilon-caprolactone) (PCL) were evaluated on the basis of the initial water activity $\left(a_{\text {wi }}\right)$ using liquid 1,1,1,2-tetrafluoroethane (R-134a) as solvent media at 2.5 MPa. Polymer yields and molecular weights were directly related to $a_{w i}$ and reaction times. The highest molecular weight $\left(M_{\mathrm{n}}\right)$ was $83,600 \mathrm{gmol}^{-1}, M_{\mathrm{w}} / M_{\mathrm{n}} 1.4$, with a $67 \%$ yield after $48 \mathrm{~h}$ of reaction with the lowest biocatalyst $a_{\text {wi }}$ preparation $\left(a_{w i}<0.16\right)$. It is suggested that the enhanced solubility of the growing polymer chains in liquid R-134a may be responsible for the attainment of such high molecular weight. A maximum polymer yield of $99 \%$ with $M_{\mathrm{n}} 7,246 \mathrm{gmol}^{-1}$ and $M_{\mathrm{w}} / M_{\mathrm{n}} 4.5$ was attained when the biocatalyst was adjusted to $a_{\mathrm{wi}}=0.22$.
\end{abstract}

\section{Introduction}

The interest in biocatalysis, in safer and non-toxic solvents has recently increased, following the principles of green chemistry [1]. According to that, supercritical fluids such as carbon dioxide and other green solvents have been investigated in enzymatic synthesis of aliphatic polyesters. Takamoto et al. were first to report in 2001 the use of supercritical carbon dioxide $\left(\mathrm{scCO}_{2}\right)$ as solvent media for the lipasecatalysed ring opening polymerization (ROP) of lactones [2], and the molecular weights $\left(M_{n}\right)$ reported in this and other more common solvents are in the range of $1,000 \mathrm{gmol}^{-1}$ to $50,000 \mathrm{gmol}^{-1}$ [3, 4]. Recently, liquid 1,1,1,2-tetrafluoroethane (R134a) has been asserted as a new green solvent adequate for enzyme activity with important advantages compared to others [5-8]. R-134a is non-flammable, non-toxic and generally recognized as safe (GRAS) for human health and consumption. It is not considered a volatile organic compound (VOC) and does not deplete the ozone layer [5]. Compared to compressed $\mathrm{CO}_{2}$, liquid $\mathrm{R}-134 \mathrm{a}$ is relatively polar with a dipole moment of 2.05 and dielectric constant $\varepsilon=9.5 \mathrm{kHz}$, which enhance the solubility of polar compounds. It presents low viscosity $\left(0.21 \mathrm{cP}\right.$ at $\left.25^{\circ} \mathrm{C}\right)$ and lower surface tension $\left(8.7 \times 10^{-3} \mathrm{~N} / \mathrm{m}\right)$ than common organic solvents $\left(17 \times 10^{-3}-73 \times 10^{-3} \mathrm{~N} / \mathrm{m}\right)$. Liquid $\mathrm{R}-134 \mathrm{a}$ is also reported to be relatively hydrophobic, which favours the retention of water molecules on the active site of the enzyme for sustained activity [7]. Besides, it requires a relatively low pressure to become liquid ( $<1 \mathrm{MPa}, \mathrm{RT})$, which represents an operational advantage over other compressed fluids (CFs) media [8]. The present work aims to report the enzymatic ring-opening (eROP) in liquid R-134a solvent media to achieve higher molecular weight polylactones. 


\section{Results and discussion}

The evaluation of the lipase-catalysed ROP of epsilon-caprolactone (CL) in liquid R$134 \mathrm{a}$ was focused on the effect of the initial water activity $\left(a_{w i}\right)$ of the biocatalyst as this is considered a crucial parameter for the biocatalyst activity [9]. Water activity is defined as the ratio of water partial pressure in the system divided by its vapor pressure. This thermodynamic parameter is frequently used to represent the amount of available water molecules required to maintain enzyme conformation flexibility, essential for catalysis. The experimental results obtained for biocatalyst preparations adjusted at varying $a_{\text {wi }}$ within a range of $<0.16$ to 0.75 are summarized in Table 1 . ${ }^{1} \mathrm{H}$ NMR and ${ }^{13} \mathrm{C}$ NMR analyses of the obtained PCL samples were in agreement with those reported elsewhere [10].

Tab. 1. Effect of $a_{w i}$ in the eROP of CL in liquid R-134a.

\begin{tabular}{|c|c|c|c|c|c|}
\hline Entry & $a_{w i}{ }^{a}$ & $\begin{array}{c}\text { Time } \\
\text { (h) }\end{array}$ & $\begin{array}{c}\text { Polymer } \\
\text { yield } \\
(\%)\end{array}$ & $\mathrm{Mn} \times 10^{-3}$ & PDI \\
\hline 1 & $<0.16^{c}$ & 12 & 57 & 22.5 & 2.8 \\
\hline 2 & $<0.16^{c}$ & 24 & 60 & 34.3 & 2.7 \\
\hline 3 & $<0.16^{c}$ & 48 & 67 & 83.6 & 1.4 \\
\hline 4 & $<0.16^{c}$ & 72 & 63 & 18.6 & 4.5 \\
\hline 5 & 0.22 & 12 & 73.3 & 10.1 & 3.5 \\
\hline 6 & 0.22 & 24 & 82.5 & 6.7 & 4.7 \\
\hline 7 & 0.22 & 48 & 99 & 7.2 & 4.5 \\
\hline 8 & 0.22 & 72 & 76.5 & 7.3 & 4.7 \\
\hline 9 & $0.44^{b}$ & 12 & 62.8 & 0.4 & 1.1 \\
\hline 10 & $0.44^{b}$ & 24 & 67.4 & 2.6 & 2.7 \\
\hline 11 & $0.44^{b}$ & 48 & 76.5 & 2.5 & 3.7 \\
\hline 12 & $0.44^{b}$ & 72 & 66.7 & 3.0 & 3.2 \\
\hline 13 & 0.44 & 12 & 61.5 & 2.7 & 3.4 \\
\hline 14 & 0.44 & 24 & 77.2 & 2.8 & 3.6 \\
\hline 15 & 0.44 & 48 & 64.1 & 2.9 & 3.5 \\
\hline 16 & 0.44 & 72 & 71.9 & 2.7 & 3.4 \\
\hline 17 & 0.75 & 12 & 54.7 & 2.5 & 3.0 \\
\hline 18 & 0.75 & 24 & 57.3 & 2.8 & 2.7 \\
\hline 19 & 0.75 & 48 & 50.7 & 2.3 & 3.2 \\
\hline 20 & 0.75 & 72 & 36 & 1.3 & 4.5 \\
\hline 21 & Blank $^{d}$ & 48 & - & - & - \\
\hline
\end{tabular}

\footnotetext{
a Water content was adjusted by saturated salts and measured at the initial conditions

${ }^{\mathrm{b}}$ Activated Molecular Sieves (MS) were added to the reactor prior to reaction

${ }^{\mathrm{c}}$ Water content was adjusted by drying overnight the system

${ }^{\mathrm{d}}$ Blank was carried out by using steam-sterilized enzyme
}

The experiment in entry 21 in Table 1 shows that enzyme activity is essential for the polymerization process. Overall results in Table 1 indicate that $a_{w i}$, or water available, has a strong influence on polymer yield and molecular weight. Graphically, the effect of $a_{\mathrm{wi}}$ on molar-mass molecular weight distributions $\left(M_{\mathrm{w}}\right)$ is shown in Figure 1. 
The maximum polymer yield of $99 \%$, with a $M_{n}$ of 7,246 as recorded by GPC/SEC analysis, was attained after $48 \mathrm{~h}$ of reaction as a white powder with a biocatalyst preparation $a_{w i}=0.22$ (entry 7 in Table 1). In contrast, the biocatalyst preparation with $a_{\mathrm{wi}}<0.16$ gave a maximum polymer yield of $67 \%$ but the highest $M_{\mathrm{n}}$ of $83,600 \mathrm{gmol}^{-1}$. White fibre-like materials were readily obtained when precipitation in cold methanol in the latter ones, in agreement with a high molecular weight recorded by GPC/SEC. It is worth to mention that the high $M_{\mathrm{n}}$ polylactone samples were easily recovered after precipitation with methanol without any filtration, as it was the case for the lower molecular weight powdery material. Save et al. have reported an interesting work regarding a correcting coefficient for the PCL $M_{\mathrm{n}}$ values from standard GPC/SEC measurements by comparing the data obtained from MALDITOF, vapour pressure osmometry and ${ }^{1} \mathrm{H} N \mathrm{NM}$ analyses. It was claimed that the real $M_{\mathrm{n}}$ values for $\mathrm{PCL}$ is approximately half of the value recorded by GPC/SEC analyses in THF and calculated from the polystyrene standards calibration curve [11]. However, the reported $M_{n}$ values in the present work have been kept relative to polystyrene standards from GPC/SEC similar to earlier reports on the eROP of CL [4, $8,12-14]$.

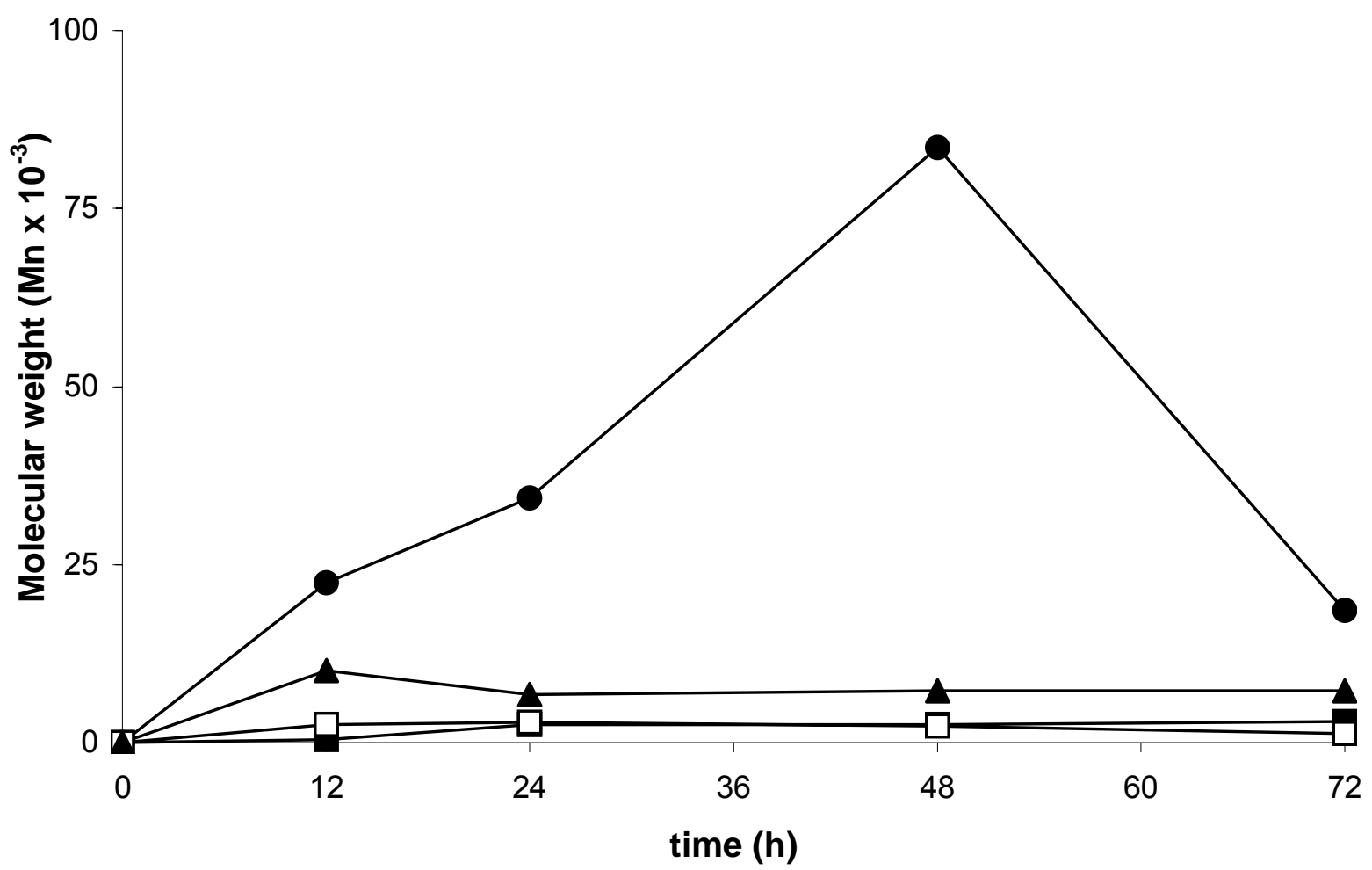

Fig. 1. Effect of $a_{w i}$ on the molecular weight $\left(M_{n}\right)$ for the lipase-catalysed ROP of CL in liquid R-134a, (口) $a_{w i}=0.75 ;(\square) a_{w i}=0.44 ;(O) a_{w i}=0.22 ;(\bullet) a_{w i}<0.16$.

Polymerization experiments carried out with $a_{\mathrm{wi}}=0.44$ and $a_{\mathrm{wi}}=0.75$ biocatalyst preparations, entries 9-16 and 17-20 in Table 1, respectively, resulted in significantly low $M_{\mathrm{n}}$ values and lower polymer yields than those attained with $a_{w i}=0.22$. In entries 9-12 activated molecular sieves (MS) were added in order to investigate whether the removal of the water generated during the chain-end activation in the system could 
drive the equilibrium reaction to products [12]. The $M_{\mathrm{n}}$ attained with added MS were significantly lower than those at $a_{w i}<0.16$ or $a_{w i}=0.22$. This points out that certain water content is required for this system, which is in agreement with earlier reports in other solvent media [13]. On the basis of the reported mechanism for the eROP of $\mathrm{CL}$, the partitioning of the water molecules from the enzyme active site to the activated MS disfavours the monomer ring-opening, as well as the enzyme regeneration from the successive enzyme-substrate intermediates.

Our findings on the lipase-catalysed synthesis of PCL in liquid R-134 with low $a_{\text {wi }}$ are in agreement with mechanistic and kinetic studies on the eROP of CL in common organic solvents and in $\mathrm{scCO}_{2}$ reported elsewhere [12-14]. According to the results for the biocatalyst adjusted at $a_{w i}<0.16$, it is suggested that the high molecular weight attained is related to the enhanced solubility of PCL in the solvent media rather than to a mechanistic explanation. The different solvent characteristics of liquid R-134a compared to toluene or $\mathrm{scCO}_{2}$ might prevent earlier precipitation of the growing polyester chains [5]. The polarity of this organic CF is similar to that of dichloromethane or tetrahydrofuran, in which the linear PCL is soluble in a wide range of molecular weights. According to our experimental evidences it results demonstrated that the polyester with up to 83,000 molecular weight is soluble in this organic CF at the operational conditions. Besides, the increase in polydispersity (PDI, $M_{w} / M_{n}$ ) recorded by GPC/SEC in entry 4 for a biocatalyst preparation at $a_{w i}$ $<0.16$, and in entry 20 for $a_{w i}=0.75$, is clearly associated to a significant reduction in $\mathrm{M}_{\mathrm{n}}$. This is in accordance with a random hydrolysis process of the ester groups resulting in the degradation of the soluble PCL chains, and an increase in the number of shorter-length polymer chains and oligomers [15-17]. Interestingly, the narrowest $\mathrm{PDI}=1.4$ was recorded with the highest $M_{n}$ (entry 3 in Table 1). However, these variations in $M_{\mathrm{n}}$ and PDI from 48 to $72 \mathrm{~h}$ of reaction were not observed for polymerizations at intermediate $a_{\text {wi }}$ biocatalyst preparations, which might well be an indication that reaction equilibrium has reached.

\section{Conclusions}

Molecular weights $M_{n}$ up to 83,601 with narrow polydispersity of polylactone PCL can be achieved by eROP when liquid R-134a is used as solvent media at relatively low pressures. This may be related to the enhanced solubility of the growing polyester chains in liquid R-134a. The experimental evidences strongly suggest that this novel green media represents an attractive solvent for the enzymatic synthesis of polyesters and other polymers of major interest. Such high molecular weight fibre might result in a polyester with improved performance, extending the applications of this biodegradable polymer, especially to those scientific and industrial areas where green synthesis of superior biomaterials are in constant demand.

\section{Experimental part}

\section{Materials}

epsilon-Caprolactone (Aldrich, USA, 98\%) was distilled under vacuum (30 mmHg, 90 ${ }^{\circ} \mathrm{C}$ ) over $\mathrm{CaH}_{2}$ and kept in a flask with activated molecular sieves $(3 \AA)$ at $5{ }^{\circ} \mathrm{C}$ until use. Chloroform, dichloromethane and methanol (technical grade, Química Barsa, Mexico) were used as supplied. Tetrahydrofuran HPLC grade (J.T. Baker, Mexico) was used as supplied. The R-134a (Dupont, SUVA, USA) cylinder was supplied by Refracciones Star, (Mexico) with $98 \%$ purity. The enzyme catalyst Novozym-435 was 
a gift from Novozymes (Mexico) and consisted of $\sim 10 \%$ by wt of lipase $B$ from Candida antarctica with a specific activity of 7,000 $\mathrm{PLUg}^{-1}$ supported on a macro porous acrylic resin (Lewatit VPOC 1600).

\section{Characterization of samples}

The number and weight-average molecular weights of the PCL samples were measured by gel permeation chromatography/size exclusion chromatography (GPC/SEC) with two different columns (Shodex KF-604 and KF-806M) mounted on a Waters Model 1525 with binary pump and absorbance detector. The columns were eluted with THF (flow rate of $0.5 \mathrm{~mL} / \mathrm{min}$ at $343.15 \mathrm{~K}$ ) and calibrated with polystyrene standards. The polyesters formed were characterized using proton $\left({ }^{1} \mathrm{H}\right)$ and carbon $\left({ }^{13} \mathrm{C}\right)$ NMR spectroscopy recorded on a Varian Unity Innova at $400 \mathrm{MHz}$. Deuterated chloroform $\left(\mathrm{CDCl}_{3}\right)$ was used as solvent with tetramethylsilane (TMS) as internal reference.

\section{Polymerization procedure}

The Novozym-435 biocatalyst beads $(3.5 \mathrm{~g})$ were placed in a $100 \mathrm{ml}$ stainless steel 316 home made reactor equipped with a magnetic stirrer driven by external stirrer plates. The reactor inlet valve (Swagelock, USA) was connected by tubing to an ISCO high-pressure syringe pump (ISCO Corp, Model 260X, USA), which was connected to the R-134a cylinder valve. The pressurizing column of the ISCO syringe pump was cooled by a refrigerant bath (American Heto Labs. Inc., US). The outlet valve (Swagelock, USA) was connected to an oil vacuum pump (Vaccubrand, USA). The equipment, from the sealed reactor to the R-134a cylinder valve, was extensively dried by the vacuum pump (30 $\mathrm{mmHg}, \mathrm{RT}, 12 \mathrm{~h})$. At these conditions the water molecules tightly bound to the biocatalyst were the only source of water in the system. Such conditions corresponds to $a_{\mathrm{wi}}<0.16$ as this is the lowest measurable value by the hygrometer (Awquick, Rotronic Instrument Corp., USA). Then, the reactor inlet valve was closed and immediately after the vacuum in the reactor was released, CL $(35 \mathrm{ml})$ was quickly transferred and the reactor was sealed again. R134 was pumped into the reactor through the ISCO syringe pump. The reactor was heated with a ceramic jacket and the operational temperature was monitored by two independent thermocouples measuring the temperature on the heating jacket and inside the reactor. The operational temperature and pressure were adjusted at $65 \pm 1$ ${ }^{\circ} \mathrm{C}$ and $2.5 \pm 0.2 \mathrm{MPa}$, respectively, in all polymerization experiments. For the polymerizations at different $a_{\text {wi }}$ of the biocatalyst preparations, the Novozym-435 beads were pre-equilibrated for $48 \mathrm{~h}$ in desiccators at reduced pressure containing saturated salt solutions of $\mathrm{CH}_{3} \mathrm{COOK}, \mathrm{K}_{2} \mathrm{CO}_{3}$, and $\mathrm{NaCl}$ for $a_{\mathrm{wi}}=0.22, a_{\text {wi }}=0.44$ and $a_{w i}=0.75$, respectively. The equilibrium water activity of the biocatalyst prior to reaction was determined in control samples with the hygrometer. The preequilibrated biocatalyst and the dried monomer were then transferred at atmospheric pressure to the reactor, which was previously dried by the oil vacuum pump. For experiments with activated molecular sieves, the pellets $(3 \AA)$ were activated in an oven $\left(120{ }^{\circ} \mathrm{C}, 12 \mathrm{~h}\right)$ prior to addition to the reactor. For control experiments with sterilized enzyme the biocatalyst was deactivated at $120{ }^{\circ} \mathrm{C}$ for $1 \mathrm{~h}$ in an autoclave (Hirayama, Amerex Inst. Inc. US). The depressurization of the reactor to atmospheric pressure at the end of each experiment proceeded easily after cooling the reactor in a conventional freezer $\left(-5^{\circ} \mathrm{C}\right)$ for a period no longer than $30 \mathrm{~min}$. The reaction mixture was dissolved in dichloromethane or chloroform and the insoluble biocatalyst 
beads were removed by filtration. The solvent was then partially evaporated under reduced pressure and the concentrates were precipitated in cold methanol to yield the PCL. The PCL samples were dried under vacuum (30 $\mathrm{mmHg}, \mathrm{RT}, 12 \mathrm{~h}$ ) and weighed to determine the polymer yields.

\section{Acknowledgements}

We thank DGAPA for postdoctoral grant (RGA) and CONACyT project $N^{\circ} 48641$ for financial support. We thank Salvador Lopez Morales from the Instituto de Investigaciones en Materiales (UNAM) for GPC analyses.

\section{References}

[1] Poliakoff, M.; Anastas, P. Nature 2001, 413, 257.

[2] Takamoto, T.; Uyama, H.; Kobayashi, S. e-Polymers 2001 no 004.

[3] Kobayashi, S.; Uyama, H.; Kimura, S. Chem. Rev. 2001, 101, 3793.

[4] Loecker, F.C.; Duxbury, C.J.; Kumar, R.; Gao, W.; Gross, R.A.; Howdle, S.M. Macromolecules 2004, 37, 2450.

[5] Corr, S. J. Fluorine Chem. 2002, 118, 55.

[6] Wood, C.D.; Senoo, K.; Martin, C.; Cuellar, J.; Cooper, A.I. Macromolecules 2002, $35,6743$.

[7] Saul, S.; Corr, S.; Micklefield, J. Angew. Chem. Int. Ed. 2004, 43, 5519.

[8] García-Arrazola, R.; Gimeno, M.; Bárzana, E. Macromolecules Comm. Edt. 2007, 40, 4119.

[9] Mora-Pale, M.J.; Pérez-Munguia, S.; Gonzalez-Mejia, J.C.; Dordick, J.S.; Bárzana, E. Biotechnol. Bioeng. 2007, 98, 535.

[10] Cordova, A.; Iversen, T.; Hult, K.; Martinelle, M. Polymer 1998, 39, 6519.

[11] Save, M. ; Schappacher, M. ; Soum, A. Macromol. Chem. Phys. 2002, 203, 889.

[12] Mei, Y.; Kumar, A.; Gross, R. Macromolecules 2003, 36, 5530.

[13] Panova, A.A.; Kaplan, D.L. Biotechnol. Bioeng. 2003, 84, 103.

[14] Utrecht, K.J.; Heise, A.; deGeus, M.; Villarroya, S.; Zhou, J.; Wyatt, M.F.; Howdle, S.M. Macromolecules 2006, 39, 7967.

[15] Matsumura, S.; Ebata, H.; Toshima, K. Macromol. Rapid Commun. 2000, 21, 860.

[16] Kobayashi, S.; Uyama, H.; Takamoto, T. Biomacromolecules 2000, 1, 1.

[17] Ebata, H.; Toshima, K.; Matsumura, S. Biomacromolecules 2000, 1, 511. 